\title{
KESAN TEKNIK PEER INSTRUCTION DENGAN PENGGUNAAN SUMBER-SUMBER SEJARAH TERHADAP PENCAPAIAN MATA PELAJARAN SEJARAH
}

\section{THE IMPACT OF PEER INSTRUCTION TECHNIQUE WITH USING HISTORICAL SOURCES ON HISTORY SUBJECT ACHIEVEMENT}

\author{
M. Kaviza \\ Pusat Pengajian Pendidikan dan Bahasa Moden, Universiti Utara Malaysia. \\ (Email: kavizakaviza@yahoo.com)
}

Received date: $14-10-2018$

Revised date: $18-12-2018$

Accepted date: $19-07-2019$

Published date: 12-09-2019

To cite this document: Kaviza, M. (2019). Kesan Teknik Peer Instruction dengan Penggunaan Sumber-sumber Sejarah Terhadap Pencapaian Mata Pelajaran Sejarah. International Journal of Education, Psychology and Counseling, 4 (32), 12-19.

DOI: $10.35631 /$ IJEPC.432002

\begin{abstract}
Abstrak: Kajian ini bertujuan untuk mengkaji kesan teknik Peer Instruction dengan penggunaan sumber-sumber sejarah terhadap pencapaian mata pelajaran sejarah dalam kalangan murid. Kajian ini merupakan kajian eksperimen dengan reka bentuk PreExperimental Design: One Group Pretest-Posttest Design yang melibatkan seramai 25 orang murid Tingkatan Empat dari sebuah sekolah menengah harian melalui teknik persampelan bertujuan. Instrumen kajian ini terdiri daripada ujian pencapaian yang telah dibina oleh pengkaji yang telah disahkan oleh pakar penilai dalam bidang pendidikan sejarah serta mempunyai nilai kebolehpercayaan, indeks kesukaran dan indeks diskriminasi yang baik. Data kajian ini dianalisis secara deskriptif dan inferensi iaitu ujian ANOVA dengan pengukuran berulang melalui perisian pengkomputeran IBM SPSS. Dapatan kajian ini menunjukkan bahawa murid-murid dapat meningkatkan min pencapaian mata pelajaran sejarah yang lebih tinggi dalam ujian pasca dan ujian lanjutan daripada ujian pra secara berterusan walaupun selepas tamatnya intervensi. Kajian ini diharapkan dapat dijadikan sumber rujukan kepada guru sejarah dalam merancang kaedah pengajaran dan pembelajaran sejarah yang inovatif selaras dengan perkembangan pembelajaran abad ke-21.
\end{abstract}

Kata Kunci: Pencapaian Mata Pelajaran Sejarah, Sumber-Sumber Sejarah, Teknik Peer Instruction

Abstract: The purpose of this study is to examine impact of peer instruction technique with using historical sources on history subject achievement among students. This is an experimental study using Pre Experimental Design: One Group Pretest - Posttest Design with involving 25 students of daily secondary schools in north of peninsular Malaysia using 
purposive sampling technique. The achievement test which has been developed and verified by the content expert and has a good reliability value, discrimation and difficulty index are used in this study.The data were analysed using descriptive and inferential statictics such as Repeated-measured ANOVA test using "IBM SPSS Statictics"computer programme. The findings of this study indicated that students showed higher history subject achievement means on post-test and extended test compared than pre test.This study is suggested that combination of peer instruction technique and using historical sources as effective teaching and learning methods to implement in history education in $21^{\text {st }}$ century.

Keywords: History Subject Achievement, Peer Instruction Technique, Historical Sources

\section{Pengenalan}

Mata pelajaran sejarah merupakan mata pelajaran teras yang dipelajari secara berterusan dari sekolah rendah hingga ke sekolah menengah (Pusat Perkembangan Kurikulum (PPK), 2003). Penekanan tentang kepentingan mata pelajaran sejarah dimulai pada tahun 2013 yang telah mewajibkan mata pelajaran sejarah sebagai syarat lulus Sijil Pelajaran Malaysia (SPM) yang merupakan suatu usaha untuk mengikis amalan murid yang melabelkan mata pelajaran sejarah sebagai mata pelajaran penghafalan. Dengan pengiktirafan ini, maka perubahan dalam kaedah pengajaran adalah dicadangkan bagi memupuk kesedaran dalam diri murid dengan menyemai semangat patriotik, menanam nilai-nilai murni, meningkatkan minat dan menyematikan kemahiran berfikir (Pusat Perkembangan Kurikulum [PPK], 2003). Justeru, pelaksanaan teknik Peer Instruction dengan penggunaan sumber-sumber sejarah merupakan salah satu usaha inovasi dalam kaedah pengajaran dan pembelajaran sejarah yang berpotensi dilaksanakan di dalam kelas selaras dengan objektif kurikulum sejarah yang ditetapkan.

\section{Sorotan Kajian}

\section{Penggunaan Sumber-sumber Sejarah}

Sumber-sumber sejarah sebagai karya-karya yang menyediakan maklumat yang berkaitan dengan sesuatu fakta, kejadian atau siri sesuatu peristiwa sejarah yang berlaku pada masa lalu (Suntharalingam, 1985). Terdapat dua jenis sumber-sumber sejarah iaitu sumber primer dan sumber sekunder. Sumber primer iaitu merujuk kepada sumber seperti catatan, laporan, surat, buku harian, dokumen, rekod dan sebagainya yang bersifat asli yang dapat memberikan maklumat, catatan atau melaporkan mengenai ssuatu peristiwa yang berlaku (Hazri Jamil, 2003; Library of Congress, 2006). Manakala, sumber sekunder pula dirujuk sebagai sumber yang tidak asli yang dihasilkan oleh sejarahwan melalui penulisan mereka seperti enskliopedia, majalah, buku teks, risalah dan sebagainya (Hazri Jamil, 2003; Library of Congress, 2006). Penggunaan sumber-sumber sejarah dalam proses pengajaran dan pembelajaran sejarah dapat menggalakkan proses berfikir kritis dan meningkatkan kebolehan intelektual murid kerana ianya melibatkan proses pengumpulan dan pemeriksaan bukti, penilaian sumber, penganalisaan sumber dan interpretasi sumber sejarah (Haydn et al, 2001; Renuka Ramakrishnan \& Siti Hawa Abdullah, 2012; Hazri Jamil, 2003; Wineburg, 1991).

\section{Teknik Peer Instruction}

Bagi memastikan murid-murid dapat terlibat secara aktif terhadap bahan pengajaran dan pembelajaran dalam membina kemahiran penaakulan yang kompleks, maka teknik Peer Instruction yang diasaskan oleh Eric Mazur merupakan salah satu teknik pengajaran dan pembelajaran Sejarah yang berpotensi dilaksanakan bagi meningkatkan pencapaian dalam 
kalangan murid. Secara umumnya, teknik Peer Instruction merupakan teknik pengajaran dan pembelajaran yang diperkenalkan dalam mata pelajaran fizik yang berpusatkan murid dengan menggunakan ujian konsep untuk meningkatkan penglibatan dan penguasaan secara mendalam serta mengelakkan berlakunya miskonsepsi pemahaman konseptual dalam kalangan murid (Crouch \& Mazur, 2001; Mazur, 1997; Porter, Bailey, Simon, Cutts, \& Zingaro, 2011). Sungguhpun begitu, teknik Peer Instruction didapati berupaya untuk menyediakan persekitaran pembelajaran yang lebih berstruktur yang membolehkan muridmurid dapat mengemukakan pandangan dan idea serta membetulkan miskonsepsi dengan rakan-rakan lain (Hoekstra, 2008; Kalman, Bolotin, \& Antimora, 2010; Turpen \& Finkelstein, 2009). Ujian konsep yang telah diperkenalkan melalui teknik ini adalah dapat menyediakan pengalaman pembelajaran yang menarik, di samping dapat membantu murid untuk mengenal pasti masalah dan kesukaran yang mereka hadapi (Mazur, 1997). Terdapat tujuh langkahlangkah dalam pelaksanaan teknik Peer Instruction (Mazur, 1997) di dalam kelas adalah seperti berikut:

1. Guru mengemukakan soalan (ujian konsep)

2. Murid diberikan 1 hingga 2 minit untuk berfikir

3. Murid menjawab soalan secara individu dengan mengangkat kad jawapan

4. Murid berbincang dengan rakan sebelah berkaitan dengan pemilihan jawapan

5. Murid menjawab semula soalan dengan mengangkat kad jawapan

6. Guru memberikan maklum balas terhadap pemilihan jawapan

7. Guru memberikan penerangan kepada jawapan yang betul

Kajian-kajian lepas juga telah membuktikan bahawa teknik Peer Instruction dapat meningkatkan minat (Keiner \& Burns, 2010; Simon \& Cutts, 2012), di samping menggalakkan pembelajaran pemahaman konseptual (Crouch \& Mazur, 2001; Lasry, Mazur, \& Watkins, 2008; Nitta, 2010) dalam kalangan murid. Oleh itu, teknik Peer Instruction adalah berpotensi dilaksanakan dalam konteks pengajaran dan pembelajaran sejarah dengan melibatkan penggunaan pelbagai jenis sumber sejarah sebagai bahan pengajaran dan pembelajaran sejarah yang menarik di dalam kelas sebagai alternatif kepada pelaksanaan kaedah pengajaran tradisional.

\section{Pernyataan Masalah}

Tidak dinafikan bahawa pencapaian mata pelajaran sejarah yang kurang memuaskan adalah disebabkan oleh pelaksanaan kaedah pengajaran guru yang bercorak tradisional yang menyebabkan murid-murid beranggapan bahawa mata pelajaran sejarah sebagai mata pelajaran membosankan, sukar difahami dan tidak diminati (Anuar Ahmad, Siti Haishah Abdul Rahim \& Nur Atiqah T. Abdullah, 2009; Hazri Jamil, 2003; Azwan Ahmad, Abdul Ghani Kaneson Abdullah, Mohammad Zohir Ahmad, Abdul Rahman Abdul Aziz, 2005; Ormardin Haji Ashaari \& Yunus Muhammad, 1996; Haydn, Arthur \& Hunt, 2001).Tambahan pula, sikap guru yang bergantung dengan amalan pengajaran bercorak tradisional telah mengehadkan usaha untuk membimbing murid mengkaji sumber-sumber sejarah dan tidak memberi kesempatan kepada murid untuk meneroka bahan pengajaran dan pembelajaran sejarah yang lain (Barton \& Levistik, 2004; Dutt-Doner \& Allen, 2015; Getman-Eraso \& Culkin, 2017; Johansson, 2017; Hover, Hicks \& Dack, 2016). Sungguhpun begitu, penggunaan teknik Peer Instruction dengan pendekatan Flipped Classroom telah dibuktikan dapat meningkatkan pemahaman konsep sejarah dalam mata pelajaran sejarah (Kaviza, 2018), namun keberkesanan teknik Peer Instruction dengan penggunaan sumber-sumber sejarah masih belum diketahui walaupun ilmu sejarah dan sumber sejarah merupakan sesuatu yang tidak dapat dipisahkan sama sekali dalam kurikulum sejarah (PPK, 2003). Maka, terdapat satu 
keperluan kepada pengkaji untuk mengkaji kesan teknik Peer Instruction dengan penggunaan sumber-sumber sejarah terhadap pencapaian mata pelajaran sejarah dalam kalangan murid.

\section{Objektif, Soalan dan Hipotesis Kajian}

Objektif kajian ini ialah:

1. Mengenal pasti kesan teknik Peer Instruction dengan penggunaan sumber-sumber sejarah terhadap pencapaian mata pelajaran sejarah.

Soalan kajian ini ialah:

1. Adakah terdapat perbezaan min ujian pra, ujian pasca dan ujian lanjutan pencapaian mata pelajaran sejarah dalam kalangan murid yang mengikuti teknik Peer Instruction dengan penggunaan sumber-sumber sejarah?

Hipotesis kajian ini ialah:

$\mathrm{H}_{\mathrm{ol}}$ : Tidak terdapat perbezaan min yang signifikan ujian pra, ujian pasca dan ujian lanjutan pencapaian mata pelajaran sejarah dalam kalangan murid yang mengikuti teknik Peer Instruction dengan penggunaan sumber-sumber sejarah.

\section{Metodologi Kajian}

Kajian ini menggunakan kaedah eksperimen dengan rekabentuk Pre Experimental Design: One Group Pretest-Posttest Design (Cohen, Manion \& Morrison, 2007) iaitu murid diukur dalam ujian pra, murid diberikan rawatan selama satu bulan, ujian pasca dijalankan dengan mengukur perbezaan min ujian pra dan ujian pasca. Pengukuran ujian lanjutan pula dijalankan selepas tempoh empat minggu daripada ujian pasca bagi mengenal pasti sama ada masih terdapat kesan rawatan (Campbell \& Stanley, 1963). Kajian ini melibatkan seramai 25 orang murid Tingkatan Empat dari sebuah sekolah menengah harian di sebuah negeri di utara Semenanjung Malaysia yang dipilih melalui teknik persampelan bertujuan yang diwakili dengan dua buah kelas sedia ada sebagai sampel kajian ini (Othman Talib, 2013). Instrumen kajian ini adalah ujian pencapaian yang terdiri daripada 40 item objektif bagi topik Perkembangan di Eropah yang telah dibina sendiri oleh pengkaji serta telah disahkan oleh dua pakar penilai dalam bidang pengajaran sejarah yang berpengalaman melebihi 10 tahun. Susunan item dalam ujian pra, ujian pasca dan ujian lanjutan adalah berbeza yang bertujuan untuk mengelakkan murid daripada menghafal jawapan soalan tersebut. Nilai kebolehpercayaan ujian ditentukan melalui K20, indeks diskriminasi dan kesukaran bagi setiap item dalam kajian ini adalah baik (Nunnally, 1978; Nitko, 2004).Data kajian ini dianalisis secara statistik deskriptif dan inferensi iaitu ujian ANOVA dengan pengukuran berulang yang dianalisis dengan menggunakan perisian pengkomputeran "IBM SPSS Statistics" versi 24.

\section{Dapatan dan Perbincangan Kajian}

Adakah terdapat perbezaan min ujian pra, ujian pasca dan ujian lanjutan pencapaian mata pelajaran sejarah dalam kalangan murid yang mengikuti teknik Peer Instruction dengan penggunaan sumber-sumber sejarah?

Bagi menjawab persoalan kajian, hipotesis nul $\left(\mathrm{H}_{\mathrm{o} 1}\right)$ telah diuji pada aras kesignifikan $(p=0.05)$ seperti berikut:

$\mathrm{H}_{\mathrm{o} 1}$ : Tidak terdapat perbezaan min yang signifikan ujian pra, ujian pasca dan ujian lanjutan pencapaian mata pelajaran sejarah dalam kalangan murid yang mengikuti teknik Peer Instruction dengan penggunaan sumber-sumber sejarah. 
Berdasarkan Jadual 1, min pencapaian mata pelajaran sejarah adalah tinggi dalam ujian pasca $(M=20.80, S D=4.39)$ berbanding dalam ujian pra $(M=7.84, S D=2.61)$ dan ujian lanjutan $(M=15.72, S D=2.19)$. Keputusan ujian Multivariate bagi Wilks Lambda pada Jadual 2 yang menunjukkan bahawa terdapat kesan utama siri ujian terhadap pencapaian mata pelajaran sejarah adalah signifikan $\left[F(2,23)=152.36, p=0.00, \pi^{2}=0.93\right]$. Nilai partial eta squared, $\pi^{2}=0.93$ dalam kajian ini menunjukkan bahawa saiz kesan siri ujian terhadap pencapaian mata pelajaran sejarah adalah sangat besar (Cohen, 1988). Di samping itu, keputusan ujian kesferaan Mauchly yang tidak signifikan $(p=0.16)$ pada Jadual 3 menunjukkan bahawa andaian kesferaan matriks varian kovarians $\left[x^{2}(2)=4.28, p=0.00\right]$ adalah dipatuhi dalam kajian ini. Maka, ujian univariate dengan Sphericity assumed pada Jadual 4 mendapati bahawa terdapat kesan utama siri ujian yang signifikan bagi pencapaian mata pelajaran sejarah $\left(F=138.15, p=0.00, \pi^{2}=0.85\right)$.

Jadual 1: Statistik Deskriptif Min Pencapaian Mata Pelajaran Sejarah dalam Ujian Pra, Ujian Pasca dan Ujian Pasca Lanjutan

\begin{tabular}{lccc}
\hline & Ujian Pra & Ujian Pasca & Ujian Lanjutan \\
\hline $\mathrm{N}$ & 25 & 25 & 25 \\
\hline$M$ & 7.84 & 20.52 & 15.72 \\
\hline$S D$ & 2.61 & 4.39 & 2.19 \\
\hline
\end{tabular}

Jadual 2: Keputusan Ujian Multivariate untuk Min Pencapaian Mata Pelajaran Sejarah $\begin{array}{lllllll}\text { Kesan } & \text { Nilai } & F & \text { Hipotesis } d f & \text { Ralat } d f & p & \text { Partial Eta }\end{array}$

\begin{tabular}{cccccccc}
\hline Pencapaian & Wilks'Lambda & 0.07 & 152.36 & 2.00 & 23 & 0.00 & 0.93 \\
\hline
\end{tabular}

Pada aras kesignifikan 0.05

Jadual 3: Keputusan ujian Mauchly's $W$ untuk Min Pencapaian Mata Pelajaran Sejarah

\begin{tabular}{|c|c|c|c|c|c|c|c|}
\hline \multirow{2}{*}{$\begin{array}{l}\text { Kesan } \\
\text { dalam } \\
\text { subjek }\end{array}$} & \multirow{2}{*}{$\begin{array}{c}\text { Mauchly's } \\
W\end{array}$} & \multirow{2}{*}{$\begin{array}{l}\text { Khi kuasa } \\
\quad \text { dua }\end{array}$} & \multirow[t]{2}{*}{$d f$} & \multirow[t]{2}{*}{$p$} & \multicolumn{3}{|c|}{ Epsilon } \\
\hline & & & & & $\begin{array}{c}\text { Greenhouse- } \\
\text { Geisser }\end{array}$ & $\begin{array}{c}\text { Huynh- } \\
\text { Feldt }\end{array}$ & $\begin{array}{l}\text { Lower- } \\
\text { bound }\end{array}$ \\
\hline Siri ujian & 0.83 & 4.28 & 2 & 0.18 & 0.86 & 0.91 & 0.50 \\
\hline
\end{tabular}

Pada aras kesignifikan 0.05

Berdasarkan Jadual 5, keputusan ujian within-subject contrasts menunjukkan terdapat perbezaan siri ujian antara pasangan ujian pra-ujian pasca-ujian lanjutan yang signifikan. Selain itu, keputusan ujian Post Hoc Bonferroni pada Jadual 6 juga menunjukan terdapat perbezaan yang signifikan pada pasangan siri ujian iaitu ujian pra, ujian pasca dan ujian lanjutan terhadap min pencapaian mata pelajaran sejarah. Oleh itu, hipotesis nol $\left(\mathrm{H}_{\mathrm{ol}}\right)$ berjaya ditolak iaitu terdapat perbezaan yang signifikan bagi ujian pra, ujian pasca dan ujian lanjutan min pencapaian mata pelajaran sejarah dalam kalangan murid yang mengikuti teknik Peer Instruction dengan penggunaan sumber-sumber sejarah. Maka, pelaksanaan teknik Peer Instruction dengan penggunaan sumber-sumber sejarah adalah berkesan untuk meningkatkan min pencapaian mata pelajaran sejarah walaupun selepas tempoh intervensi telah tamat. Dapatan ini adalah selaras dengan kajian Crouch \& Mazur, (2001) dan Nitta, (2010) yang mendapati bahawa pencapaian pemahaman konseptual murid dalam mata pelajaran Fizik adalah meningkat dengan lebih tinggi bagi kumpulan murid yang menggunakan teknik Peer Instruction berbanding dengan murid yang tidak menggunakan teknik Peer Instruction. 
Jadual 4: Keputusan Ujian Within-Subject Effects untuk Min Pencapaian Mata Pelajaran Sejarah

\begin{tabular}{cccccccc}
\hline Kesan & $\begin{array}{c}\text { Jumlah } \\
\text { kuasa Dua } \\
\text { Jenis III }\end{array}$ & $\boldsymbol{d f}$ & $\begin{array}{c}\text { Kuasa } \\
\text { dua min }\end{array}$ & $\boldsymbol{F}$ & $\boldsymbol{p}$ & $\begin{array}{c}\text { Partial Eta } \\
\text { Squared }\end{array}$ \\
\hline Pencapaian & Sphericity assumed & 2049.31 & 2 & 1024.65 & 138.15 & 0.00 & 0.85 \\
\hline
\end{tabular}

Pada aras kesignifikan 0.05

Jadual 5: Keputusan Ujian Within-Subjects Contrasts untuk Min Pencapaian Mata Pelajaran Sejarah

\begin{tabular}{lccccccc}
\hline Sumber & Waktu ujian & $\begin{array}{c}\text { Jumlah } \\
\text { kuasa Dua } \\
\text { Jenis III }\end{array}$ & df & $\begin{array}{c}\text { Kuasa } \\
\text { dua min }\end{array}$ & $\boldsymbol{F}$ & $\boldsymbol{p}$ & $\begin{array}{c}\text { Partial Eta } \\
\text { Squared }\end{array}$ \\
\hline Siri & Fasa 1 vs Fasa 2 & 40.19 .56 & 1 & 4019.56 & 234.47 & 0.00 & 0.91 \\
ujian & Fasa 2 vs Fasa 3 & 576.00 & 1 & 576.00 & 30.99 & 0.00 & 0.56 \\
\hline Ralat & Fasa 1 vs Fasa 2 & 411.44 & 24 & 17.14 & & & \\
& Fasa 2 vs Fasa 3 & 446.00 & 24 & 18.58 & & & \\
\hline
\end{tabular}

Pada aras kesignifikan 0.05

Jadual 6: Keputusan Ujian Post Hoc Bonferroni untuk Min Pencapaian Mata Pelajaran Sejarah

\begin{tabular}{llccccc}
\hline & & $\begin{array}{c}\text { Perbezaan } \\
\text { Min }\end{array}$ & Ralat & $\boldsymbol{p}$ & \multicolumn{2}{c}{$\begin{array}{c}\text { 95\% selang keyakinan } \\
\text { bagi perbezaan }\end{array}$} \\
\cline { 5 - 7 } & & & & & Bawah & Atas \\
\hline Ujian Pra & Ujian Pasca & $-12.68^{*}$ & 0.83 & 0.00 & -14.81 & -10.56 \\
& Ujian Lanjutan & $-7.88^{*}$ & 0.59 & 0.00 & -9.40 & -6.36 \\
\hline Ujian & Ujian Pra & $12.68^{*}$ & 0.83 & 0.00 & 10.56 & 14.81 \\
Pasca & Ujian Lanjutan & $4.80^{*}$ & 0.86 & 0.00 & 2.59 & 7.01 \\
\hline Ujian & Ujian Pra & $7.88^{*}$ & 0.59 & 0.00 & 6.36 & 9.40 \\
Lanjutan & Ujian Pasca & $-4.80^{*}$ & 0.86 & 0.00 & -7.01 & -2.59 \\
\hline
\end{tabular}

* Pada aras kesignifikan 0.05

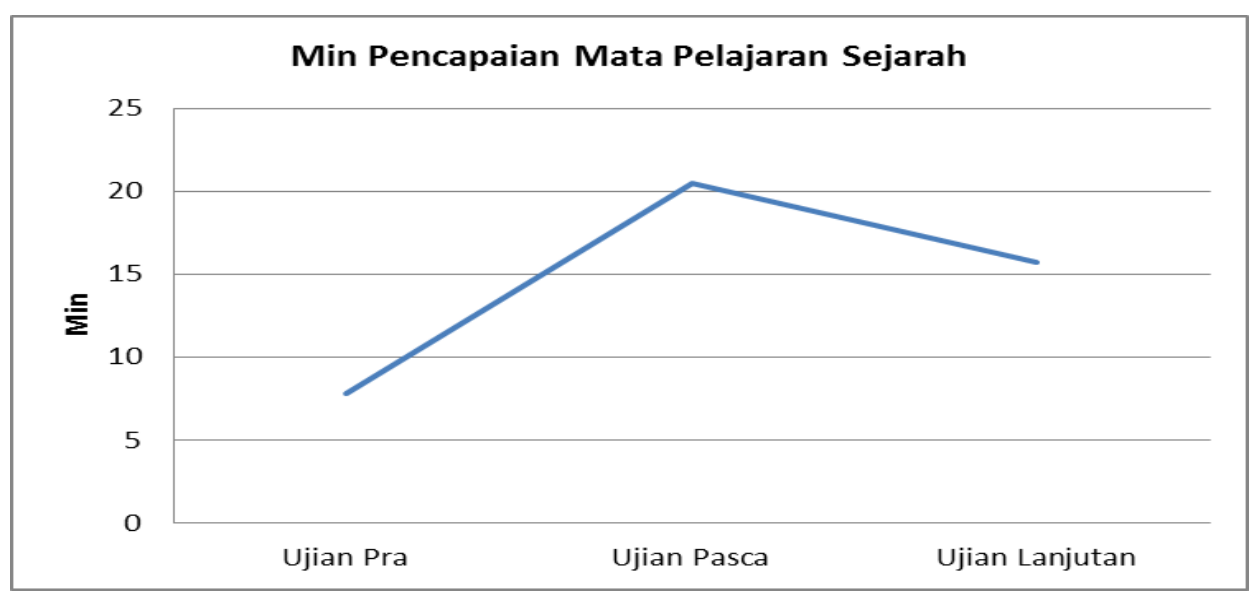

Rajah 1: Min Pencapaian Mata Pelajaran Sejarah dalam Ujian Pra, Ujian Pasca dan Ujian Lanjutan 


\section{Kesimpulan}

Secara keseluruhannya, teknik Peer Instruction dengan penggunaan sumber-sumber sejarah merupakan salah satu inovasi dalam teknik pengajaran dan pembelajaran sejarah yang berkesan yang boleh digunakan untuk meningkatkan pencapaian mata pelajaran sejarah dalam kalangan murid. Peningkatan pencapaian mata pelajaran sejarah yang lebih tinggi dalam ujian pasca dan ujian lanjutan telah menunjukkan bahawa murid-murid dapat terlibat secara aktif dalam proses penerokaan sumber-sumber sejarah yang diberikan secara mendalam bagi memahami sesuatu peristiwa sejarah. Justeru, guru-guru sejarah hendaklah mengambil langkah inisiatif untuk memperkenalkan teknik Peer Instruction dengan penggunaan sumbersumber sejarah pada semua peringkat persekolahan sama ada di sekolah rendah mahupun di sekolah menengah agar proses pengajaran dan pembelajaran Sejarah yang lebih menarik dapat dilaksanakan.

\section{Rujukan}

Anuar Ahmad, Siti Haishah Abdul Rahim \& Nur Atiqah T.Abdullah. (2009). Tahap Keupayaan Pengajaran Guru Sejarah dan Hubungannya dengan Pencapaian Murid Berprestasi Rendah. Jurnal Pendidikan Malaysia, 34(1), 53-66.

Azwan Ahmad, Abdul Ghani Kaneson Abdullah, Mohammad Zohir Ahmad \& Abdul Rahman Abdul Aziz. (2005). Kesan Efikasi Guru Sejarah terhadap Amalan Pengajaran Berbantukan Teknologi Maklumat dan Komunikasi (TMK). Jurnal Penyelidikan Pendidikan, 7, 14-26.

Barton, K., \& Levistik, L. (2004). Teaching History for the Common Good. Mahwah, New Jersey: Lawrence Erlbaum.

Campbell, D.T., \& Stanley, J.C. (1963). Experimental and Quasi-experimental Designs for Research. Chicago: Rand McNally

Cohen, L., Manion, L., \& Morrison, K. (2000). Research Methods in Education (5 ${ }^{\text {th }}$ Edition). London: Routledge Falmer.

Crouch, C.H., \& Mazur, E. (2001). Peer Instruction: Ten Years of Experiences and Result. American Journal of Physics, 69, 670-977.

Dutt-Doner, K.M. (2015). Increasing Pre-service Teachers' Capacity to Utilize and Implement Primary Source Instruction in the Elementary Classroom. National Teacher Education Journal, 8(1), 13-24.

Getman-Eraso, J., \& Culkin, K. (2017). Close Reading: Engaging and Empowering History Students through Document Analysis on e-Portfolio. International Journal of $e$ Portfolio, 7(1), 29-42.

Haydn, T., Arthur, J. \& Hunt, M. (2001). Learning to Teach History in the Secondary School: A Companion to School Experience. London: Routledge Falmer.

Hazri Jamil. (2003). Teknik mengajar Sejarah. Pahang: PTS Publications \& Distributors Sdn Bhd.

Hoekstra, A. (2008). Vibrant student voices: Exploring effects of the use of clickers in large college cources. Learning, Media, \& Technology, 33(4), 329-341.

Hover, S.V., Hicks, D., \& Dack, H. (2016). From Source to Evidence? Teachers' Use of Historical Sources in Their Classrooms. The Social studies, 107(6), 209-217.

Johansson, P. (2017). Learning study as a clinical research practice to generate knowledge about the learning of historical primary source analysis. Educational Action Research, 25(1), 167-181.

Kalman, C.S., Bolotin, M., \& Antimirova, T. (2010). Comparison of the effectiveness of collaborative groups and peer instruction in a large introductory physics course for science majors. Canadian Journal of Physics, 88(5), 325-332. 
Kaviza, M. (2018a). Kesan Penggunaan Teknik Peer Instruction dengan Pendekatan Kelas Flipped Terhadap Pencapaian Pemahaman Konsep Sejarah. Journal of ICT in Education, 5(1), 14-26.

Keiner, L.E., \& Burns, T.E. (2010). Interactive engagement: How much is enough? The Physics Teacher, 48(2), 108-111.

Lasry, N., Mazur, E., \& Watkins, J. (2008). Peer Instruction: from Harvard to the two years college. American Journal of Physics, 76(11), 1066-1069.

Library of Congress. (2006). Using Primary Sources. Retrieved from http://www.loc.gov/tecahers/using primary sources/

Mazur, E. (1997). Peer Instruction: A User's Manual. Upper Saddle River. HJ: Prentice Hall.

Nitko, A. J. (2004). Educational Assessment of Students. Ed. Ke-4. Upper Saddle River, NJ: Merril.

Nitta, H. (2010). Mathematics theory of peer instruction dynamics. Physical Review Special Topics - Physics Education Research, 6(2), 020105, 1-4.

Nunnally, J.C. (1978). Psychometrie Theory ( $2^{\text {nd }}$ Ed). New York: McGraw Hill.

Omardin Haji Ashaari \& Yunus Muhammad. (1996). Kaedah Pengajaran sejarah. Kuala Lumpur: Utusan Publication \& Distributors Sdn Bhd.

Othman Talib. (2013). Asas Penulisan Tesis Penyelidikan \& Statistik. Serdang: Penerbit Universiti Putra Malaysia.

Porter, L., Bailey, L.C., Simon, B., Cutts, Q., \& Zingaro, D. (2011). A multi- classroom report on the value of peer instruction. In Proceedings of the $16^{\text {th }}$ Annual Joint Conference on Innovation and Technology in Computer Science Education, June 27029, Darmstadt, Germany.

Pusat Perkembangan Kurikulum. (2003). Huraian Sukatan pelajaran Mata Pelajaran Sejarah Tingkatan Empat. Putrajaya: Kementerian Pendidikan Malaysia

Renuka Ramakrishnan \& Siti Hawa Abdullah. (2012). Penggunaan Sumber Digital Sejarah Dalam Kalangan Guru Sejarah. Seminar Kebangsaan Majlis Dekan, Zon Regency by the Sea Johor Bharu, 7-9 Oktober 2012.

Simon, B., \& Cutts, Q. (2012). Peer Instruction: A teaching method to foster deep understanding. Communications of the ACM, 55(2), 27-29.

Suntharalingam. (1985). Pengenalan Kepada Sejarah. Kuala Lumpur: Marican \& Sons Sdn Bhd

Turpen, C., \& Finkelstein, N.D. (2009). Not all interactive engagement is the same: Variantions in physics professors' implementation of peer instruction. Physical Review Special Topics-Physics Education Research, 5(2), 120101, 1-8.

Wineburg, S.S. (1991). On the Reading of Historical Texts: Notes on the Breach between School and Academy. American Educational Research Journal, 28(3), 495-519. 